\title{
Plot Technique Studies on Sweetpotato Yield Trials
}

\author{
Roger L. Vallejo and Humberto A. Mendoza ${ }^{2}$ \\ Breeding and Genetics Department, International Potato Center, P. O. Box 5969, Lima, Peru \\ Additional index words. Ipomoea batatas, plot size, number of replications, uniformity trial
}

\begin{abstract}
The objective of this research was to determine optimum plot size and number of replications to evaluate yield of sweetpotato (Ipomoea batatas Lam.) clones. The optimum plot size was estimated using the methods of maximum curvature and comparison of variances. The adequate number of replications was determined using the Hatheway method. Using the maximum curvature method, the estimated optimum plot size was 10 basic units (b.u. = six plants or $1.2 \mathrm{~m}^{2}$ ) for La Molina and San Ramon, and 5 b.u. for Tacna, Peru. Using the comparison of variances method, the optimum plot size was $15 \mathrm{~b}$.u. for all locations tested. The adequate number of replications with a plot size of 15 b.u. was four.
\end{abstract}

Sweetpotato has many desirable characteristics such as high yield, wide adaptability, multifunctional usage, and a wide range of nutritional components, yet requires low production inputs. These attributes make sweetpotato an attractive crop for tropical regions. However, field experiments carried out with sweetpotatoes often have large coefficients of variation (cv). This may be due in part to inherent crop variation or to inadequate field plot techniques.

Sweetpotato researchers use field trials to determine the potential of cultivars and experimental lines. In a breeding program, this procedure is a routine in which the main objective is to identify promising genotypes to be evaluated in additional trials as clonal accessions. To increase efficiency, optimum plot size and an adequate number of replications must be used.

Federer (1967) defined the experimental unit as the total amount of material to which a treatment in a particular replication is applied. The optimum plot size depends on the nature of the experimental material, experiment design, number of entries, number of replications, and available resources. The variability of the experimental material constitutes a main component of the experimental error that must be minimized using adequate experimental techniques.

In general, experimental error is reduced by increasing plot size (Immer and Raleigh, 1933; McClelland, 1926; McKenzie et al., 1964). Conversely, others found that the experimental error was reduced significantly when the number of replications rather than plot size was increased (Rampton and Petersen, 1962; Thomas and Abou-El Fittouh, 1968).

Li (1971) in Taiwan found that the optimum plot size for the winter sermon sweetpotato crop was 6 to $12 \mathrm{~m}$ long and three rows wide $\left(18\right.$ to $\left.36 \mathrm{~m}^{2}\right)$ in Changlma, and 8 to $12 \mathrm{~m}$ long and three rows wide $\left(24\right.$ to $\left.36 \mathrm{~m}^{2}\right)$ in Hsinchu. In the fall crop, the optimum plot size was 6 to $12 \mathrm{~m}$ long and two rows wide (12 to $24 \mathrm{~m}^{2}$ ) in Yunlin, and 6 to $12 \mathrm{~m}$ long and two to three rows wide $\left(12\right.$ to $\left.36 \mathrm{~m}^{2}\right)$ in Tainan.

Boudreaux and Jones (1978) used 12\% as an arbitrary level of acceptability for the $\mathrm{cv}$, and found that a one-row plot of 15 to 20 hills $30.5 \mathrm{~cm}$ apart in length $\left(4.6\right.$ to $\left.9 \mathrm{~m}^{2}\right)$ and with nine

Received for publication 18 May 1990. Accepted for publication 28 Aug. 1991. We gratefully acknowledge the technical assistance of Jorge A. Espinoza in conducting this research. This project was entirely supported by the International Potato Center. The cost of publishing this paper was defrayed in part by the payment of page charges. Under postal regulations, this paper therefore must be hereby marked advertisement solely to indicate this fact.

${ }^{1}$ Associate Geneticist

${ }^{2}$ Head of Department. to 11 replications appeared adequate to conduct research on the total weight of storage roots. A two-row plot $\left(9.1\right.$ to $\left.12.2 \mathrm{~m}^{2}\right)$. required five to seven replications, while a three-row plot (13.7 to $18.3 \mathrm{~m}^{2}$ ) required three to six replications to be equally accurate.

Hautea (1977) found that the optimum plot size was 8.10 to $9.45 \mathrm{~m}^{2}$ (36 to 42 hills). Optimum plot shape was not definitely established, but two-row plots presented the lowest variability. Biradar (1980) found that the cv decreased with an increase in plot size, while plot shape had no appreciable effect. Plot sizes of 2.88 to $3.6 \mathrm{~m}^{2}$ were optimum.

The main objective of our research was to determine optimum plot size and number of replications for efficient yield evaluation of sweetpotato cultivars. This determination was done as a function of the variability of experimental material, soil heterogeneity, and the minimum of experimental error.

\section{Materials and Methods}

The research was conducted at three locations in Peru: La Molina (altitude $238 \mathrm{~m}$ ), Tacna (altitude $100 \mathrm{~m}$ ), and San Ramon (altitude $800 \mathrm{~m}$ ). The two former locations are in coastal deserts and the latter in the hot jungle. In each location, a uniformity trial was run using I. batatus cultivars Nemañete, Morado de los Pales, and Jewel.

The uniformity trial consisted of 24 rows $54 \mathrm{~m}$ long ( $1 \mathrm{~m}$ between rows). At harvest, each row was divided into sections $1.2 \mathrm{~m}$ long (six hills) to evaluate the yield per basic unit. For the statistical analyses, the trial was subdivided following a criterion of hierarchical classification, simulating a split-plot design (Fig. 1). To determine optimum plot size and number of replications, the following methods were used:

Maximum curvature method. This method estimates the cv for each plot size. Then each plot size is plotted against its respective $\mathrm{cv}$ and a curve establishing the inverse relationship between these two variables is obtained. Finally, the point of maximum inflection is found visually. It is assumed that the location of this point corresponds to the optimum plot size (Immer, 1932; Justesen, 1932; MacDonald et al., 1939; Zuber, 1942).

Comparison of variances. In this method, the estimates of variances of average yield per basic units (b.u.) of different plot sizes $\left(\mathrm{V} \overline{\mathrm{x}}_{\mathrm{j}}\right)$ ' were considered and they are calculated by: $V \overline{\mathrm{x}}_{\mathrm{j}}=$ $\mathrm{V}^{\prime} / \mathrm{x}_{\mathrm{j}}$ where: $\mathrm{x}_{\mathrm{i}}$ is the plot size in b.u.; $\mathrm{V}_{\mathrm{j}}{ }_{\mathrm{j}}$ is the variance of various plot sizes reduced with respect to one subplot in hierarchical order, e.g., $\mathrm{V}_{1}^{\prime}=\mathrm{V}_{1} ; \mathrm{V}^{\prime}=\left[\mathrm{f}(\mathrm{e}-1) \mathrm{V}_{2}+(\mathrm{f}-1) \mathrm{V}_{1}\right] /$ $(\mathrm{ef}-1) ; \mathrm{V}^{\prime} 3=\left[\mathrm{ef}(\mathrm{d}-1) \mathrm{V}_{3}+\mathrm{f}(\mathrm{e}-1) \mathrm{V}_{2}+(\mathrm{f}-1) \mathrm{V}_{1}\right] /$ 
Table 1. Analysis of variance of sweetpotato uniformity trials in three locations following a hierarchical classification with six subdivisions. ${ }^{2}$

\begin{tabular}{|c|c|c|c|c|c|c|c|c|}
\hline \multirow[b]{2}{*}{ Source of variation } & \multirow[b]{2}{*}{ df } & \multirow[b]{2}{*}{$X_{j}$} & \multicolumn{2}{|c|}{ La Molina } & \multicolumn{2}{|c|}{ Tacna } & \multicolumn{2}{|c|}{ San Ramon } \\
\hline & & & $\mathrm{V}_{\mathrm{j}}$ & $\mathrm{V}^{\prime}{ }_{j}$ & $\mathrm{~V}_{\mathrm{j}}$ & $\mathrm{V}^{\prime}{ }_{\mathrm{j}}$ & $V_{j}$ & $V_{j}^{\prime}$ \\
\hline Replications & 5 & 180 & 17.3703 & 17.3703 & 4.6128 & 4.6128 & 36.9360 & 36.9630 \\
\hline Blocks/replications & 6 & 90 & .4 .0434 & 10.1011 & 0.6607 & 2.4571 & 20.6554 & 28.0557 \\
\hline Plots/blocks & 24 & 30 & 3.8222 & 5.7955 & 3.0364 & 2.8543 & 9.1711 & 15.1062 \\
\hline Subplots/plots & 36 & 15 & 2.1974 & 3.9711 & 2.6189 & 2.7350 & 2.6546 & 8.7927 \\
\hline Sub-subplots/subplots & 114 & 5 & 1.7721 & 2.4983 & 0.5787 & 1.2908 & 2.0468 & 4.2745 \\
\hline Sub-sub-subplots/sub-subplots & 864 & 1 & 0.8262 & 1.1593 & 0.3042 & 0.5008 & 1.7700 & 2.2690 \\
\hline
\end{tabular}

${ }^{ } \mathrm{X}_{\mathrm{j}}$, plot size in basic units; $\mathrm{V}_{\mathrm{j}}$, mean square; $\mathrm{V}_{\mathrm{j}}$, variances for different plot sizes reduced with respect to one subplot in hierarchical order.

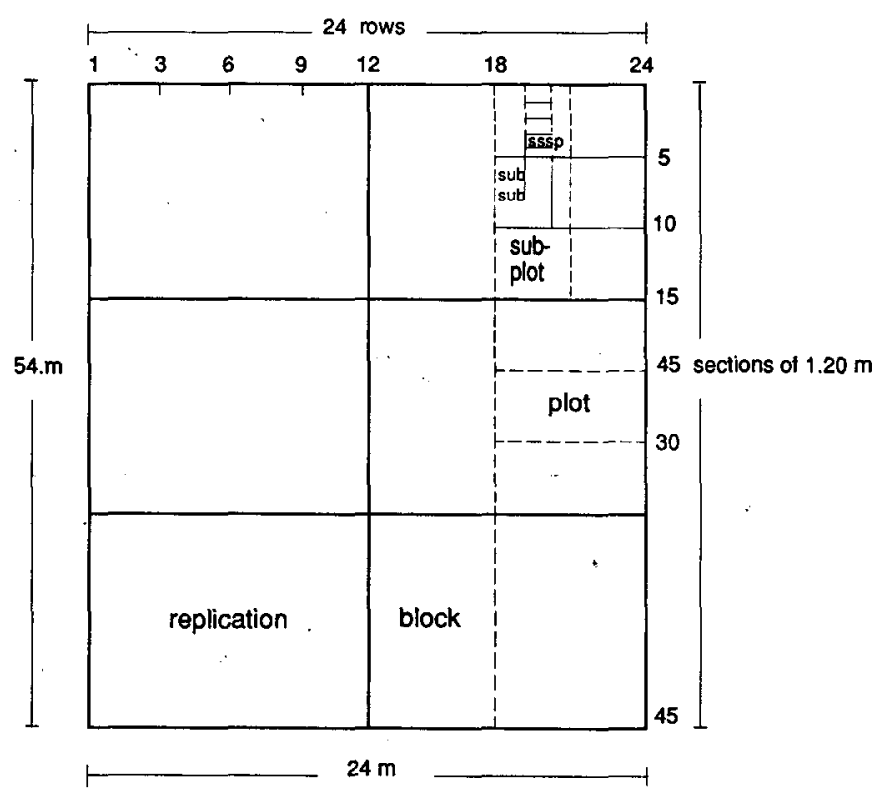

Fig. 1. Scheme for sweetpotato uniformity trials, subdivided following a hierarchical classification.

Table 2. Coefficient of variability estimates of sweetpotato trials in three locations for diverse plot sizes $\left(\mathrm{x}_{\mathrm{j}}\right)$ and number of plots $(\mathrm{n}$,$) .$

\begin{tabular}{ccccc}
\hline \hline & & \multicolumn{3}{c}{ Coefficient of variability } \\
\cline { 3 - 5 } $\mathrm{x}_{\mathrm{j}}$ & $\mathrm{n}_{\mathrm{j}}$ & La Molina & Tacna & San Ramon \\
\hline 1 & 1080 & 27.45 & 7.35 & 12.76 \\
5 & 216 & 8.04 & 2.02 & 2.74 \\
15 & 72 & 2.98 & 1.43 & 1.04 \\
30 & 36 & 1.96 & 0.77 & 0.96 \\
90 & 12 & 0.67 & 0.12 & 0.48 \\
180 & 6 & 0.69 & 0.15 & 0.32 \\
\hline
\end{tabular}

$\left(\right.$ clef - 1). .; $\mathrm{V}_{6}^{\prime}=\left[\operatorname{bcdef}(\mathrm{a}-1) \mathrm{V}_{6}+\operatorname{cdef}(\mathrm{b}-1) \mathrm{V}_{5}+\right.$ $\left.\ldots+(\mathrm{f}-1) \mathrm{V}_{1}\right] /($ abcdef -1$)$.

Consecutive tests of homogeneity of variances were performed, excluding in each test the plot of lower size in which variance was statistically different. The test was continued until a group of plot sizes with statistically similar variances was obtained. Then it was inferred that the lower plot size of the group tested corresponded to the optimum plot size. The use of a larger plot size was not justified because the estimate of variance was not significantly reduced (Vallejo and Mendoza, 1988).

Hatheway's method. True mean differences (d) were estimated using the equation proposed by Hatheway (1961). To

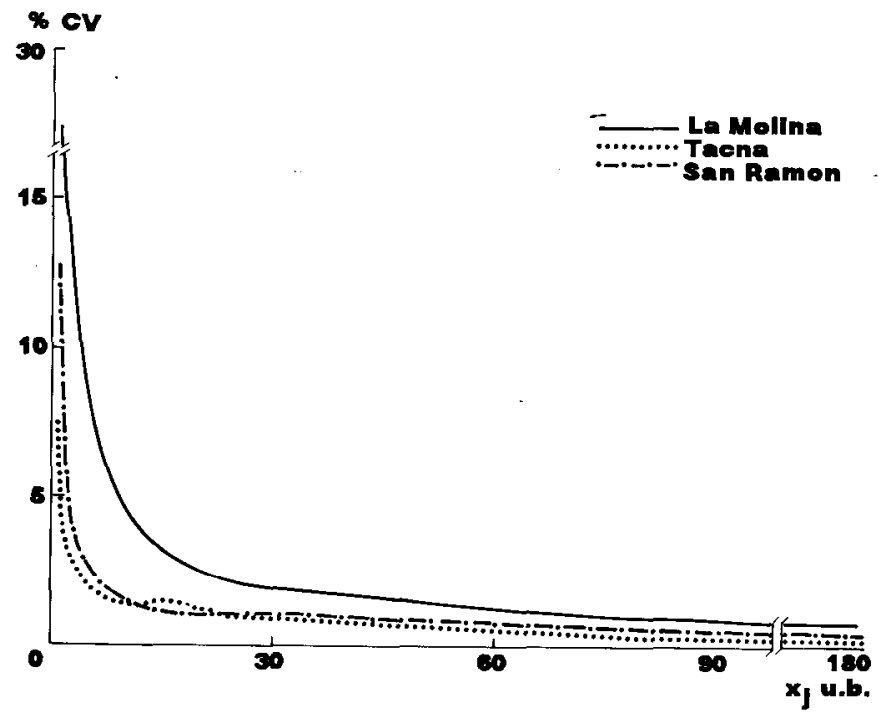

Fig. 2. Estimates of coefficient of variability for each sweetpotato plot size $\left(\mathrm{x}_{\mathrm{i}}\right)$, at three locations.

Table 3. Variance estimates of average sweetpotato yield per basic unit $\left(\mathbf{V}_{\mathbf{x}}\right)$ of different plot sizes and for three locations.

\begin{tabular}{clcl}
\hline \hline \multirow{2}{*}{$\begin{array}{c}\text { Plot size } \\
\left(\mathrm{x}_{\mathrm{i}}\right)\end{array}$} & \multicolumn{3}{c}{ Estimates of $\sqrt{\mathbf{x}_{\mathbf{j}}}$} \\
\cline { 2 - 4 } & La Molina & Tacna & San Ramon \\
\hline 1 & $1.1593 \mathrm{a}$ & $0.5008 \mathrm{a}$ & $2.2690 \mathrm{a}$ \\
5 & $0.4996 \mathrm{~b}$ & $0.2581 \mathrm{~b}$ & $0.8549 \mathrm{~b}$ \\
15 & $0.2648 \mathrm{C}$ & $0.1823 \mathrm{C}$ & $0.5862 \mathrm{C}$ \\
30 & $0.1932 \mathrm{C}$ & $0.0951 \mathrm{c}$ & $0.5035 \mathrm{c}$ \\
90 & $0.1122 \mathrm{c}$ & $0.0273 \mathrm{C}$ & $0.3117 \mathrm{c}$ \\
180 & $0.0965 \mathrm{C}$ & $0.0256 \mathbf{C}$ & $0.2052 \mathrm{C}$ \\
\hline
\end{tabular}

'Separation of estimates by Bartlett's test $(\alpha=0.05)$,

detect these differences, several combinations of number of treatments $(5,10,15,20,25$, and 30) and number of replications $(2,3,4,5,6$, and 7$)$ were used. In addition, the use of a randomized complete block (RCB) design and an optimum plot size estimated for each location were considered. The equation used was: $d=\left[2\left(t_{1}+t_{2}\right)^{2} \mathrm{cv}\right] / \mathrm{rx}^{\mathrm{b}}$ where: $\mathrm{t}_{1}$ is the critical Student's value for a significant level of $\alpha=0.05$; $t_{2}$ is the tabular Student's value for $(1-P)=0.20$, where $P$ is the probability to obtain a significant result; $\mathrm{cv}$ is the plot size coefficient of variability included in the estimation; $r$ is the number of replications considered; $x$ is the plot size; $b$ is the weighted coefficient of soil heterogeneity (Hatheway and Williams, 1958). 
Table 4. Estimates of true differences of treatment means (\%) for various combinations of sweetpotato entry numbers and replications in a randomized complete block design at three locations. ${ }^{2}$

\begin{tabular}{lcccccc}
\hline \hline \multirow{2}{*}{$\begin{array}{l}\text { Location and } \\
\text { replications }\end{array}$} & 10 & 15 & 20 & 25 & 30 & 35 \\
\cline { 2 - 6 } La Molina & & \multicolumn{5}{c}{ Entries (no.) } \\
2 & 23.62 & 21.26 & 20.83 & 20.60 & 20.44 & 20.35 \\
3 & 17.06 & 16.71 & 16.56 & 16.45 & 16.41 & 16,37 \\
4 & 14.50 & 14.30 & 14.21 & 14.17 & 14.14 & 14.11 \\
5 & 12.77 & 12.72 & 12.67 & 12.64 & 12.59 & 12.49 \\
6 & 11.66 & 11.58 & 11.53 & 11.50 & 11.40 & 11.40 \\
7 & 10.76 & 10.70 & 10.65 & 10.56 & 10.56 & 10.56 \\
Tacna & & & & & & \\
2 & 15.32 & 14.67 & 14.37 & 14.18 & 14.11 & 14.04 \\
3 & 11.77 & 11.53 & 11.43 & 11.35 & 11.33 & 11.30 \\
4 & 10.00 & 9.84 & 9.81 & 9.78 & 9.76 & 9.71 \\
5 & 8.81 & 8.87 & 8.74 & 8.72 & 8.69 & 8.62 \\
6 & 8.05 & 7.99 & 7.96 & 7.91 & 7.87 & 7.87 \\
7 & 7.42 & 7.37 & 7.35 & 7.28 & 7.28 & 7.28 \\
San Ramon & & & & & \\
2 & 24.46 & 23.42 & 22.95 & 22.70 & 22.52 & 22.42 \\
3 & 18.80 & 18.41 & 18.24 & 18.11 & 18.08 & 18.04 \\
4 & 15.97 & 15.76 & 15.66 & 15.62 & 15.59 & 15.55 \\
5 & 14.07 & 14.01 & 13.96 & 13.92 & 13.88 & 13.76 \\
6 & 12.85 & 12.76 & 12.75 & 12.67 & 12.56 & 12.56 \\
7 & 11.85 & 11.79 & 11.74 & 11.63 & 11.63 & 11.63 \\
\hline
\end{tabular}

${ }^{2}$ Estimates made using optimum plot size of 15 basic units, $\alpha=0.05$, and $(1-P)=0.20$.

\section{Results and Discussion}

The analysis of variance (ANOVA) of the uniformity trial including mean squares $\left(\mathrm{V}_{\mathrm{i}}\right)$ and the variances for different plot sizes reduced with respect to one subplot in hierarchical order $\left(\mathrm{V}^{\prime}\right)$ for each location are shown in Table 1.

Maximum curvature method. Using the ANOVA (Table 1), the cv for each plot size and location was calculated (Table 2). In general, an increase in plot size up to 15 b.u. significantly reduced the $\mathrm{CV}$, after which there was little effect. Figure 2 shows the inverse relationship between plot sizes and their cv for the three locations. The points of maximum curvature were visually located at 10 b.u. for La Molina and San Ramon and 5 b.u. for Tacna. Optimum plot size was 60 plants $\left(12 \mathrm{~m}^{2}\right)$ for the first two locations and 30 plants $\left(9 \mathrm{~m}^{2}\right)$ for the last one.

Comparison of variances method. The variance of average yield per basic unit $\left(\mathrm{V}_{\mathbf{i}}\right)$ for different plot sizes and for each location was estimated (Table 3 ). These data confirm the inverse relationship existing between the plot sizes and their respective variances because the variances of means tend to decrease with increased plot size.

Afterward, we found for all locations that variances for plot sizes of $15,30,90$, and 180 b.u. were statistically similar using consecutive tests of homogeneity of variance. Optimum plot size was 15 b.u. because variance was not reduced significantly when larger plot sizes were used. This optimum plot size was equivalent to plots of 90 plants $\left(18 \mathrm{~m}^{2}\right)$.

Hatheway's method. Plots of 15 units were used to estimate true differences of treatments (d) for combinations of number of treatments and replications in a RCB design and for each location (Table 4). In general, experimental precision improved if the number of replications was increased. Precision was significantly increased up to four replications where true differences of treatments near $15 \%, 10 \%$, and $16 \%$ were detected at La Molina, Tacna, and San Ramon, respectively. These d values are acceptable by statistical inference, which suggested that the use of four replications was adequate when an optimum plot size of 15 b.u. was used. Where resources are limited, three replications could be used with slightly reduced precision.

Our results indicate that no significant increases in either plot size or number of replications will contribute individually to appreciable reduction of experimental error. It seems that a balanced increase of these two components, within reasonable and manageable margins, will increase experimental accuracy.

We have found both coincidence and discrepancy in our research compared with previous experimental work on field plot techniques. Experimental materials, soil types, environmental conditions, and statistical procedures may explain the discrepancies.

In our research, three very different cultivars were used and soil conditions and environmental characteristics of the testing sites differed substantially. However, the statistical procedures were standard. Under these conditions, and accepting certain variations within a reasonable limit, the following conclusions can hold for the three experiment stations where the research was done: 1) Optimum plot size was 10 b.u. for La Molina and San Ramon and 5 b.u. for Tacna (using maximum curvature method). 2) Optimum plot size of 15 b.u. was found for $\mathrm{La}$ Molina, Tacna, and San Ramon (using comparison of variances method). 3) Since the comparison of variances method is more reliable, we recommend the use of experimental plots of 15 b.u.; or 90 plants $\left(18 \mathrm{~m}^{2}\right)$. 4) The adequate number of replications was estimated as four for all locations tested (using Hatheway's method).

\section{Literature Cited}

Biradar, R.S. 1980. Field plot technique studies on sweet potato. J. Root Crops 6(1/2): 15-19.

Boudreaux, J.E. and L.G. Jones. 1978. Field plot studies with sweet potato. J. Amer. Soc. Hort. Sci. 103:87-89.

Federer, W.T. 1967. Experimental design. Indian ed. State College Agr., Cornell Univ., Ithaca, N.Y. p. 59-85.

Hatheway, W.H. 1961. Convenient plot size. Agron. J. 53:279-280. 
Hatheway, W.H. and E.J. Williams. 1958. Efficient estimation of the relationship between plot size and the variability of crop yields. Biometrics 14:207-222.

Hautea, R.A. 1977. Best plot size for sweet potato variety trials. BSA Thesis, Univ. of the Philippines, Los Baños.

Immer, F.R. 1932. Size and shape of plot in relation to field experiments with sugar beets. J. Agr. Res. 44:649-668.

Immer, F. and S.M. Raleigh. 1933. Further studies of sizes and shape of plot relative to field experiments with sugar beets. J. Agr. Res. 47:212-215.

Justesen, S.H. 1932. Influence of size and shape of plots on the precision of field experiments with potatoes. J. Agr. Sci. 22:366372.

Li, L. 1971. Studies on the sampling techniques in field trials with sweet potato. J. Agr. Assn. China 73:9-22.

MacDonald, D., W.L. Fielding, and D.F. Ruston. 1939. Experimental methods with cotton. I. The design of plots for variety trials. J. Agr. Sci. 29:35-47.
McClelland, C.K. 1926. Some determinations of plot variability. Agron. J. 18:819-823.

McKenzie, H., N.D. Holmes, L.K. Peterson, and M.N. Grant. 1964. A comparison of three plot sizes in studies of host resistance to the wheat stem sawfly. Can. J. Plant Sci. 44:485.

Rampton, H.H. and R.G. Petersen. 1962. Relative efficiency of plot size and numbers of replications as indicated by yields or orchard grass seed in a uniformity test. Agron. J. 54:247-249.

Thomas, H.L. and H.A. Abou-El Fittouh. 1968. Optimum plot size and number of replications for estimating forage yield and moisture percentage. Agron. J. 60:549-550.

Vallejo, R.L. and H.A. Mendoza. 1988. Determination of optimum plot size and adequate number of replications to evaluate potato seedling populations. Proc. VII Symp. Intl. Soc. Trop. Root Crops, Gosier (Guadaloupe), 1-6 July 1985. Eel. Institut Natimal de la Recherche Agronomique, Paris, 1988. p. 835-856.

Zuber, M.S. 1942. Relative efficiency of incomplete block designs using corn uniformity trial data. J. Amer. Soc. Agron. 34:30-47. 